\title{
Friction and Wear Behavior of AlTiN-Coated Carbide Balls Against SKD11 Hardened Steel at Elevated Temperatures
}

\author{
Rui Wang ${ }^{1,2} \cdot$ Hai-Juan Mei ${ }^{1} \cdot$ Ren-Suo $\mathrm{Li}^{2} \cdot$ Quan Zhang ${ }^{1} \cdot$ Teng-Fei Zhang ${ }^{1} \cdot$ Qi-Min Wang ${ }^{1}$
}

Received: 2 January 2018/Revised: 21 February 2018/Published online: 30 May 2018

(C) The Chinese Society for Metals and Springer-Verlag GmbH Germany, part of Springer Nature 2018

\begin{abstract}
In this study, AlTiN coatings were deposited on YT14 cemented carbide balls by arc ion plating technique. The friction and wear behavior of the AlTiN-coated balls against SKD11 hardened steel was investigated by sliding tests using a ball-ondisk tribometer at various temperatures from 25 to $700{ }^{\circ} \mathrm{C}$ in air. The results showed that the friction and wear behavior was significantly influenced by the testing temperature. Obvious fluctuations were observed in the friction curves at elevated temperatures, which could be attributed to the formation and rupture of unstable $\mathrm{Fe}$ and $\mathrm{Cr}$ oxide layers. As the temperature increased from 25 to $500{ }^{\circ} \mathrm{C}$, the wear rate of the coated balls increased from the scale of $10^{-21}-10^{-20} \mathrm{~m}^{3} /$ $\mathrm{N} \mathrm{m}$, and then decreased to $10^{-22} \mathrm{~m}^{3} / \mathrm{N} \mathrm{m}$ as the temperature further increased to $700{ }^{\circ} \mathrm{C}$. It was also found that the friction and wear behavior of the coated balls was directly dependent on the counterpart materials. As the temperature increased, the main wear mechanism of the coated balls changed from mild abrasive wear and adhesive wear to abrasive wear failure at $500{ }^{\circ} \mathrm{C}$, and then transferred to adhesive wear and mild oxidation wear at $700{ }^{\circ} \mathrm{C}$. For SKD1 1 hardened steel, the primary wear mechanism changed from delamination wear to abrasive wear and then transferred to plastic deformation and fatigue wear, accompanied by adhesive wear and tribo-oxidation wear.
\end{abstract}

Keywords AlTiN $\cdot$ SKD11 hardened steel $\cdot$ Elevated temperatures $\cdot$ Friction and wear

\section{Introduction}

Compared to binary TiN coating, the ternary AlTiN coating exhibits higher hardness, better wear and oxidation resistance at elevated temperatures [1-3]. Therefore, AlTiN coatings have been widely used as protective coatings for the cutting tools in high-speed and dry machining conditions [4-6]. The service behavior of coated components in most engineering application is determined by the coatingsubstrate bonding strength and the tribological properties of the coatings. Once the bonding strength is solved, the

Available online at http://link.springer.com/journal/40195

Teng-Fei Zhang

tfzhang@gdut.edu.cn

$\triangle$ Qi-Min Wang

qmwang@gdut.edu.cn

1 School of Electromechanical Engineering, Guangdong University of Technology, Guangzhou 510006, China

2 School of Mechanical Engineering, Guilin University of Aerospace Technology, Guilin 541004, China tribological properties would be the main factor to determine the service behavior of the coated components [7]. The wear mechanism of hard coatings changes with the increase in cutting temperature due to softening of the coatings and substrates, the release of internal stress and oxidation under high-temperature condition [8]. Recently, many studies have been performed on the applications of AlTiN coatings, and their tribological properties have also been widely investigated [9-11].

It has been reported that the counterparts, e.g., $\mathrm{SiC}$ ball, $\mathrm{Si}_{3} \mathrm{~N}_{4}$ ball, and $\mathrm{Al}_{2} \mathrm{O}_{3}$ ball, have different influence on the friction and wear behavior of the nitride coatings during sliding tests under different temperatures [12-14]. Polcar et al.'s [13] work showed that the friction coefficient of the $\mathrm{CrN}$ coatings against $\mathrm{Si}_{3} \mathrm{~N}_{4}$ ball decreased with temperature, while the lowest value was obtained at room temperature against $\mathrm{Al}_{2} \mathrm{O}_{3}$ balls. With respect to the friction and wear behavior of the AlTiN coatings sliding against $\mathrm{Al}_{2} \mathrm{O}_{3}$ ball, the dominant wear mechanism changed from mild adhesive wear to plastic deformation when the test temperature increased over than $800{ }^{\circ} \mathrm{C}[15,16]$. The wear mechanism of the AlTiN coatings against $\mathrm{Si}_{3} \mathrm{~N}_{4}$ ball at 
high temperatures was primarily composed of oxidation wear and abrasive wear, accompanied by fatigue wear and adhesive wear [17]. Therefore, the friction and wear behavior of the AlTiN coatings is not only dependent on the test temperatures, but also significantly dependent on the counterpart materials during the sliding tests. Due to the outstanding mechanical and tribological properties, AlTiN-coated tools have been widely used for the highspeed cutting of hardened steel SKD11 (62 HRC), and the highest transient temperatures in the tool-workpiece contact zone can reach to approximately $840{ }^{\circ} \mathrm{C}$ during the high-speed machining [18]. For the uncoated tools, adhesive wear and abrasive wear were main wear mechanism, while for the AlTiN-coated tools, adhesive wear became dominant during high-speed milling of the SKD11 hardened steel [19]. However, the counterparts, e.g., $\mathrm{Si}_{3} \mathrm{~N}_{4}$ ball and $\mathrm{Al}_{2} \mathrm{O}_{3}$ ball, will not well reflect the real friction and wear behavior of the coated carbide tools in high-speed cutting and milling of hardened steels. It is well known that friction and wear are not intrinsic properties of materials. Instead, they are the response of sliding surfaces under the applied test conditions [20]. Due to high toughness and excellent wear resistance, the hardened steel SKD11 has been widely applied in the production of die, spindle and jigs. During the high-speed machining, the tool-workpiece contact zone is heated instantaneously, which will affect the performance of coatings on cutting tools. However, the cutting temperature is easily affected by the surroundings and is difficult to measure accurately. Obviously more experimental work is needed to understand the dependence of friction and wear behavior of the AlTiN-coated tools against SKD11 hardened steel at elevated temperatures.

Thus, the objective of the present work is to investigate the tribological properties of AlTiN-coated carbide balls against SKD11 hardened steel by using a ball-on-disk tribometer at elevated temperatures up to $700{ }^{\circ} \mathrm{C}$, and to find out the wear mechanism of the coated balls depending on the test temperatures, which are necessary to understand the dominant failure patterns of the coated carbide tools at elevated temperatures. Notably, the friction pair of AlTiNcoated balls and SKD11 hardened steel could simulate well the cutting conditions to some extent, which could provide explanations for failure mechanisms of the coated carbide tools in high-speed and dry machining process.

\section{Experimental}

\subsection{Coating Deposition}

AlTiN coatings were deposited on the polished YT14 (WC-14\% TiC-8\%Co) cemented carbide substrates by arc ion plating using a $\mathrm{Ti}_{33} \mathrm{Al}_{67}$ alloy target $(\varnothing 100 \mathrm{~mm}$, purity
$99.5 \%)$. The cemented carbide specimens $(17 \mathrm{~mm} \times 17$ $\mathrm{mm} \times 4 \mathrm{~mm}$ ) were used for characterizing the microstructure and mechanical properties, and the coated cemented carbide balls $(\varnothing 6 \mathrm{~mm})$ were used as counterparts against the SKD11 hardened steel $(17 \mathrm{~mm} \times 17$ $\mathrm{mm} \times 4 \mathrm{~mm}$ ) during the sliding tests. All the specimens were cleaned ultrasonically in acetone and alcohol for $15 \mathrm{~min}$ and then dried in air before being put into the vacuum chamber. Prior to deposition, the chamber was evacuated to a base pressure of $5.0 \times 10^{-3} \mathrm{~Pa}$ and then heated up to a working temperature of $500{ }^{\circ} \mathrm{C}$. In order to remove the surface contaminates, the substrates were etched by an argon-ion-etching process for $30 \mathrm{~min}$ at a gas pressure of 2.0 Pa with a bias voltage of $-1000 \mathrm{~V}$. A CrN adhesion layer with a thickness of $\sim 200 \mathrm{~nm}$ was deposited using $\mathrm{Cr}$ target for 10 min under the working pressure of $0.5 \mathrm{~Pa}$. The deposition time was maintained at $60 \mathrm{~min}$ to obtain the AlTiN coatings with a total thickness of $4.0 \pm 0.2 \mu \mathrm{m}$. The detail deposition parameters are listed in Table 1.

\subsection{Coating Characterization}

The morphology and chemical composition of the coating were observed by scanning electron microscopy (SEM, FEI, Nano430) equipped with an energy-dispersive X-ray spectrometer (EDS). The crystal structure of the coating was characterized by X-ray diffraction (XRD, D8 Advance) using $\mathrm{Cu} K_{\alpha}$ radiation $(\lambda=0.154 \mathrm{~nm})$ as an $\mathrm{X}$-ray source, and the scanning was recorded in the range $30^{\circ}-80^{\circ}$ with a $0.02^{\circ}$ step size. The coating hardness was measured by nanoindenter (CSM, NHT2) with a Berkovich diamond indenter. The indentation depth was fixed at $10 \%$ of the coating thickness to minimize the substrate effect. The scratch test of the coating was performed by a micro-scratch tester (CSM, RST) using Rockwell C indenter with a radius of $200 \mu \mathrm{m}$. The coating was scratched with increasing load from $0 \mathrm{~N}$ to a maximum of $100 \mathrm{~N}$, and the scratch length was $3 \mathrm{~mm}$ with the scratch speed of $6 \mathrm{~mm} / \mathrm{min}$.

The friction and wear behavior of the AlTiN-coated balls against SKD11 hardened steel was conducted by using a high-temperature ball-on-disk tribometer (CSM, THT) in air at $25,300,500$, and $700{ }^{\circ} \mathrm{C}$. The schematic diagram of this friction test is shown in Fig. 1. The workpiece material of SKD11 hardened steel was used as the counterpart against the coated cemented carbide balls. The chemical composition and hardness of SKD11 hardened steel are given in Table 2. The sliding tests were conducted with a rotational speed of $400 \mathrm{r} / \mathrm{min}$ under a load of $2 \mathrm{~N}$ and a relative humidity of $55 \pm 5 \%$. To avoid the AlTiN-coated balls being easily worn out, only 1000 sliding cycles were performed in the friction tests against 
Table 1 Deposition parameters of the AlTiN coating

\begin{tabular}{llll}
\hline Parameters & Ar glow discharge & CrN adhesion layer & AlTiN layer \\
\hline Bias voltage (V) & -1000 & -120 & -120 \\
Flow rate (sccm) & $300(\mathrm{Ar})$ & $140\left(\mathrm{~N}_{2}\right)$ & $300\left(\mathrm{~N}_{2}\right)$ \\
Working pressure (Pa) & 2.0 & 0.5 & 1.2 \\
Cathode current (A) & 0 & 100 & 80 \\
Time (min) & 30 & 10 & 60 \\
\hline
\end{tabular}

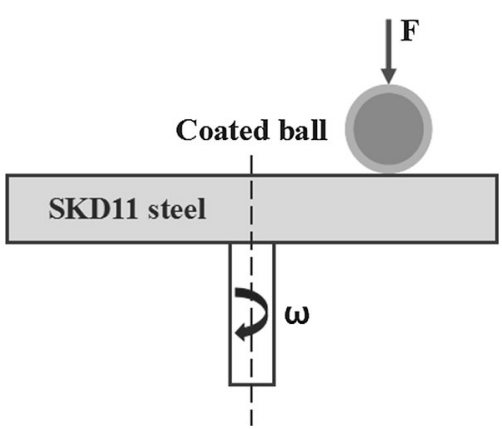

Fig. 1 Schematic diagram of our high-temperature ball-on-disk tribological test

SKD11 hardened steel. After the friction tests, the surface hardness of SKD11 hardened steel outside the wear tracks was evaluated by using a micro-Vickers tester with an applied load of $500 \mathrm{gf}$. The morphologies of the wear tracks were observed by optical microscopy (OM) and scanning electron microscopy (SEM, FEI, Nano430). The wear rates of the coated balls were calculated as the worn volume per normal load and the sliding distance. The wear volumes were evaluated from the wear cap images taken in an optical microscopy (OM), according to the equation as follows:

$V=\frac{1}{3} \pi h^{2} \cdot(3 R-h), h=R-\sqrt{R^{2}-\frac{d^{2}}{4}}$,

where $V$ is the wear volume loss in $\mu \mathrm{m}^{3}, R$ is the coated ball radius in $\mu \mathrm{m}, h$ and $d$ refer to the wear scar depth and diameter in $\mu \mathrm{m}$, respectively.

\section{Results and Discussion}

\subsection{Microstructure and Mechanical Properties}

The surface and cross-sectional SEM images of the asdeposited coating are shown in Fig. 2. It can be seen that the AlTiN coating exhibited a relatively uniform and smooth surface with only a few white particles with different sizes (maximum diameter was $\sim 0.93 \mu \mathrm{m}$ ) dispersed on the surface, which were caused by metal droplets injected during coating deposition by AIP technique [22]. As displayed in Fig. $2 b$, the multilayer structure can be clearly distinguished. The $\mathrm{CrN}$ layer was well adhered to the cemented carbide substrates and no obvious defects (e.g., pores and holes) were observed. The top AlTiN layer exhibited a dense and fine-grained structure without significant columnar features, and the combination with the adhesion layer was compact. As can be determined from the cross-sectional SEM image, the total thickness of the AlTiN coating was approximately $4.0 \mu \mathrm{m}$, which indicated a relatively high deposition rate.

Figure $2 \mathrm{c}$ presents the XRD pattern of the AlTiN coating, which exhibited an FCC TiN phase (ICDD 38-1420) with (111) (200) and (220) peaks being detected. All the peaks shifted toward higher diffraction angle, suggesting the solid solution of $\mathrm{Al}$ atoms in the FCC TiN lattice, and formed a complete solid-solution phase of FCC-Ti(Al)N. The intensity of the (200) peak was much higher than that of the (111) and (220) peaks, indicating a (200) preferred orientation. Compared with other crystal planes, the orientation (200) crystal plane with the lowest surface energy could be expected when the surface energy was ultimately dominant [23].

The chemical composition and mechanical properties of the AlTiN coating are listed in Table 3. The composition of the as-deposited AlTiN coating was measured by EDS, and the atomic ratios of $\mathrm{Al}, \mathrm{Ti}$, and $\mathrm{N}$ were $29.65,15.39$, and 54.96 at.\%, respectively. The AlTiN coating showed the higher content of $\mathrm{Al}$ than that of $\mathrm{Ti}$, which can improve the hardness and oxidation resistance of the AlTiN coating [17]. Moreover, the AlTiN coating exhibited a relatively high hardness of $33.3 \mathrm{GPa}$ and elastic modulus of approximately $483.5 \mathrm{GPa}$. The high hardness of the coating could be attributed to hardening by solid solution of the $\mathrm{Al}$
Table 2 Chemical composition and hardness of the SKD11 hardened steel [21]

\begin{tabular}{llllllllll}
\hline Material & Hardness & \multicolumn{6}{l}{ Chemical composition (at.\%) } \\
\cline { 3 - 9 } & & $\mathrm{Cr}$ & $\mathrm{C}$ & $\mathrm{Mo}$ & $\mathrm{Mn}$ & $\mathrm{Si}$ & $\mathrm{V}$ & $\mathrm{P}$ \\
\hline SKD11 & $62 \mathrm{HRC}$ & $11.0-13.0$ & $1.4-1.6$ & $0.7-1.2$ & $\leq 0.6$ & $\leq 0.6$ & $0.15-0.3$ & $<0.03$ \\
\hline
\end{tabular}




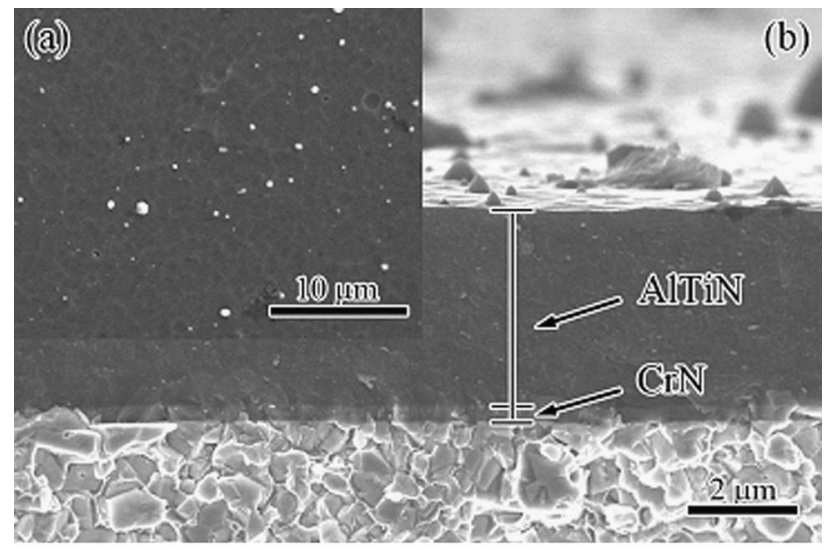

(c)

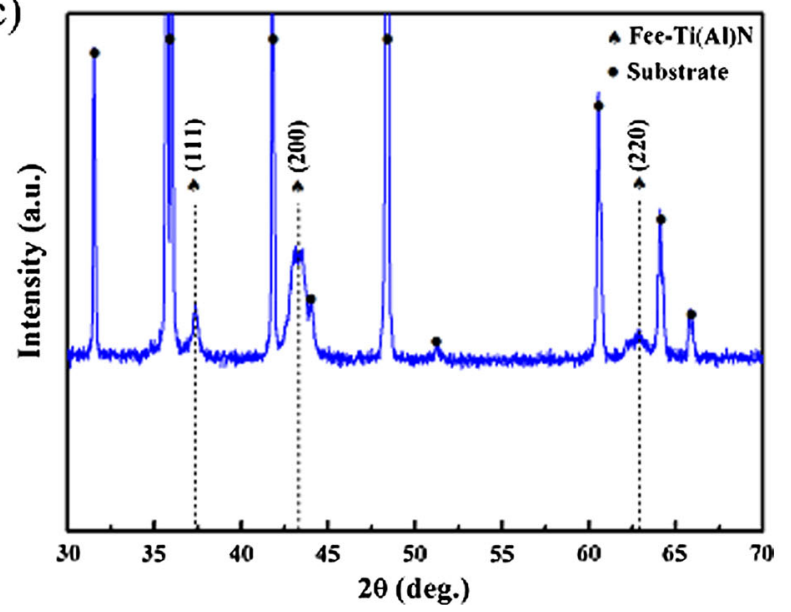

Fig. 2 a Surface morphology, b cross-section SEM morphology and c X-ray diffraction pattern of the AlTiN coating onto the cemented carbide substrate

elements, which decreased the lattice constant of the coating [24]. Meanwhile, the critical load of the as-deposited coating measured by the scratch-test method (Lc2) was about $48.5 \mathrm{~N}$.

\subsection{Friction and Wear Behavior}

It is well known that friction coefficient is closely related to many factors such as temperature, friction pair material, normal load [25]. In this study, effect of the temperature on the friction coefficient was investigated. Figure 3 shows the friction coefficient as a function of the sliding distance of the AlTiN-coated balls against SKD11 hardened steel at various temperatures. As shown in Fig. 3, the initial

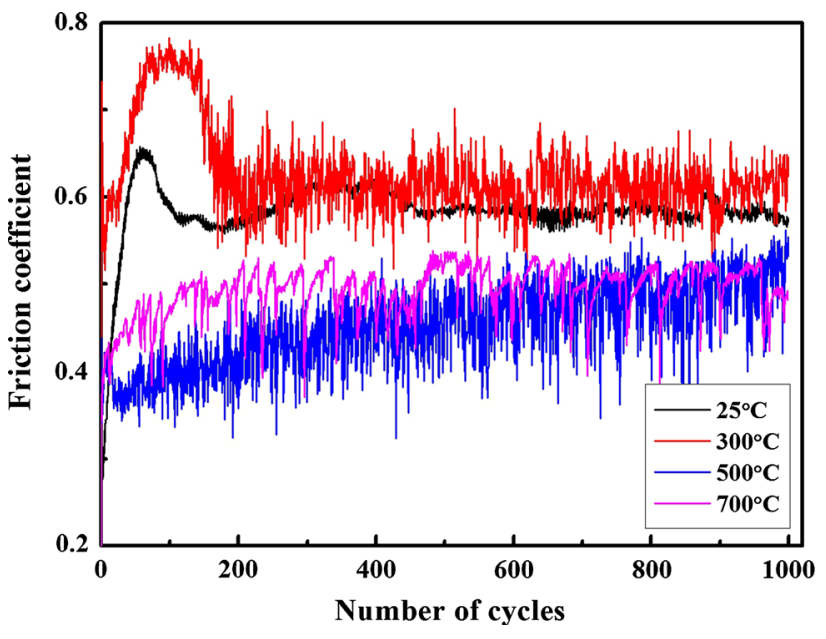

Fig. 3 Friction coefficient of the AlTiN-coated balls against SKD11 hardened steel at different temperatures

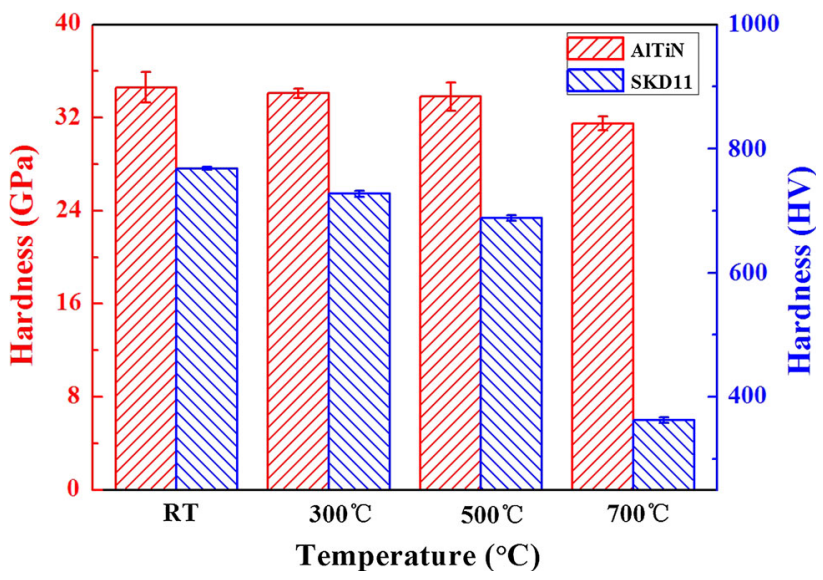

Fig. 4 Hardnesses of the AlTiN coating and SKD11 hardened steel after friction tests at various temperatures

running-in phase was represented by a rapid increase of the friction coefficient, which was found to be a result of the transition in contact condition from two-body abrasion to interfacial sliding [26]. It can be clearly seen that the initial running-in phase was shortened with the increase in the temperature, and the friction coefficient was quite stable without noticeable fluctuation during the tests at room temperature. However, the significant fluctuations were observed in the friction curves as the wear temperature increased, which should be attributed to the formation

Table 3 Chemical composition and mechanical properties of the AlTiN coating

\begin{tabular}{llllll}
\hline Coating & Chemical composition (at.\%) & Thickness $(\mu \mathrm{m})$ & Hardness $(\mathrm{GPa})$ & Elastic modulus $(\mathrm{GPa})$ & Adhesion strength $(\mathrm{N})$ \\
\hline \multirow{2}{*}{ AlTiN } & $\mathrm{Al}(29.65)$ & & & & $48.5 \pm 0.8$ \\
& $\mathrm{Ti}(15.39)$ & $4.0 \pm 0.2$ & $33.3 \pm 1.6$ & $483.5 \pm 30.1$ & \\
\hline
\end{tabular}




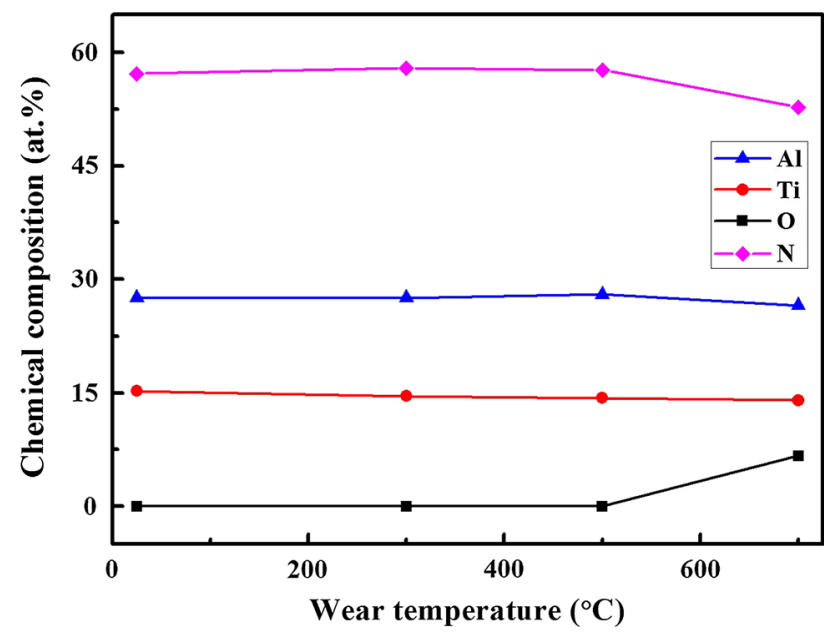

Fig. 5 Chemical composition of the coated ball outside the wear scar analyzed by EDS
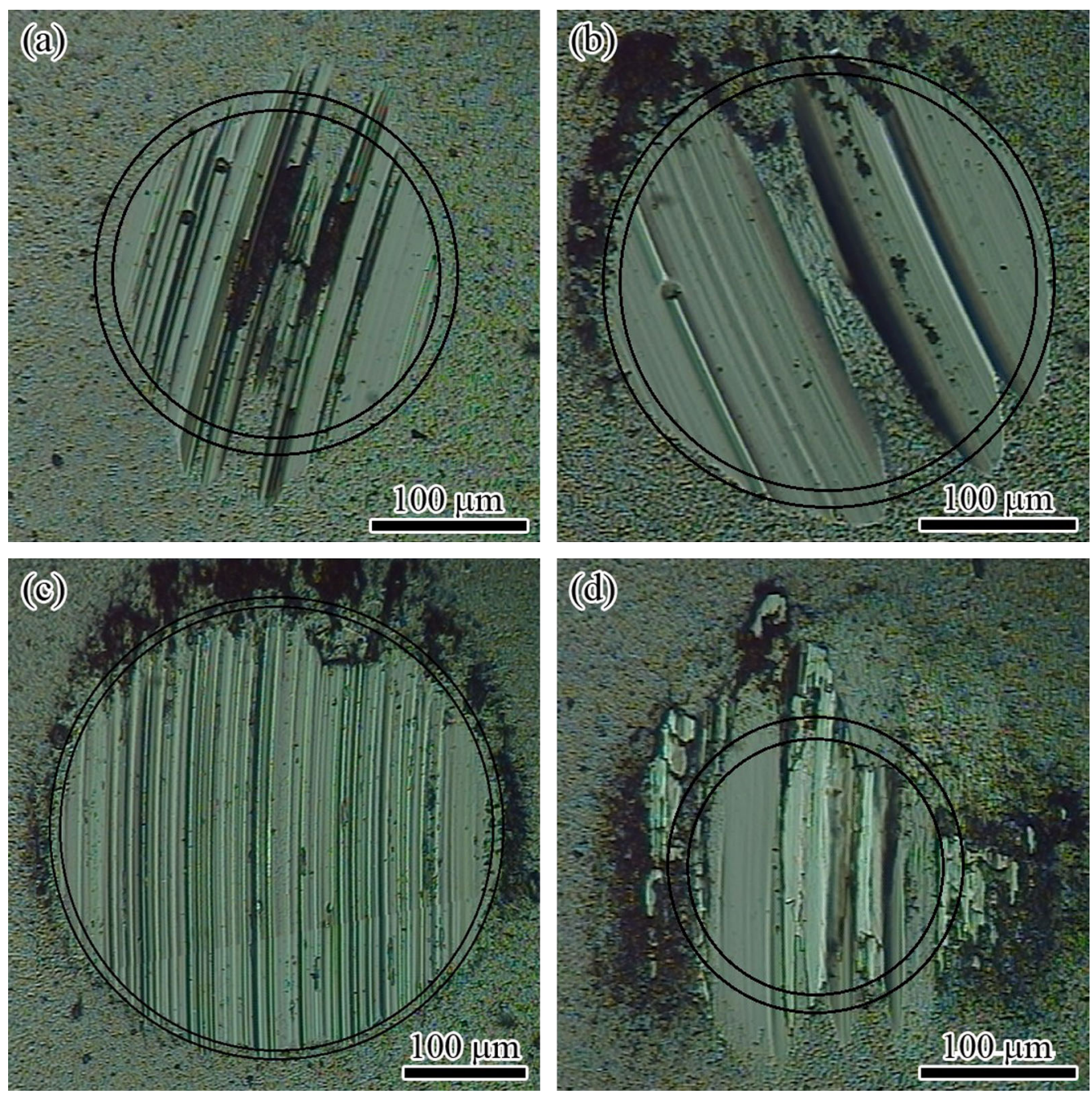

Fig. 6 Optical images of the wear scar of AlTiN-coated balls after friction tests at different temperatures: a $25{ }^{\circ} \mathrm{C}, \mathbf{b} 300{ }^{\circ} \mathrm{C}, \mathbf{c} 500{ }^{\circ} \mathrm{C}, \mathbf{d ~} 700{ }^{\circ} \mathrm{C}$ 

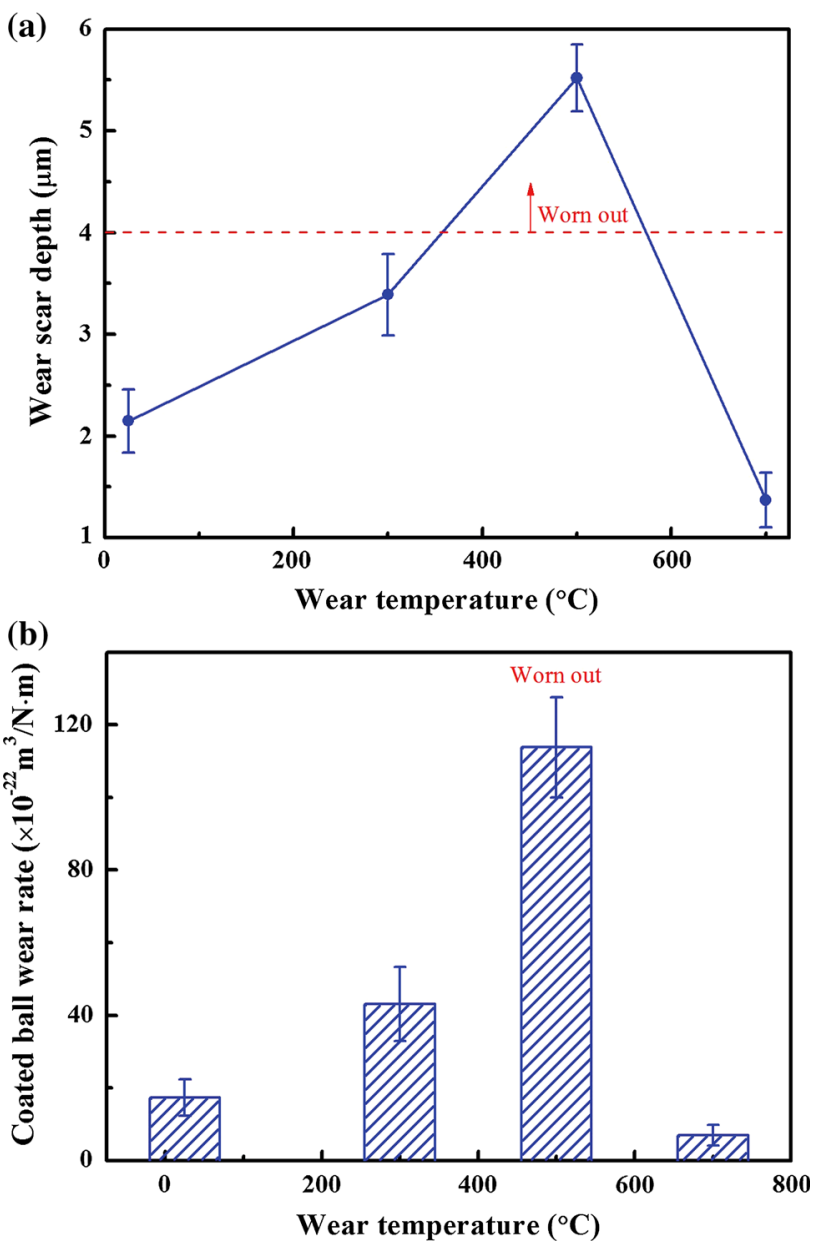

Fig. 7 a Wear scar depth and $\mathbf{b}$ wear rate of the AlTiN-coated balls after friction tests at different temperatures

coatings annealed at temperature range from 25 to $500{ }^{\circ} \mathrm{C}$ was observed. As the temperature further increased to $700{ }^{\circ} \mathrm{C}$, a limited content of oxygen was detected outside wear scar by the EDS analysis (Fig. 5), indicating that the surface of AlTiN coating was slightly oxidized. Therefore, the hardness showed a slight decrease from $34.6 \mathrm{GPa}$ (asdeposited) to $31.5 \mathrm{Gpa}\left(700{ }^{\circ} \mathrm{C}\right)$, respectively. For SKD11, the hardness decreased slightly from 768.2 to $688.0 \mathrm{HV}$ when the temperature increased from 25 to $500{ }^{\circ} \mathrm{C}$. The hardness of SKD11 hardened steel decreased sharply to $362.4 \mathrm{HV}$ when the temperature increased to $700{ }^{\circ} \mathrm{C}$, which probably caused the severe oxidation and thermal softening effect [29]. It was reported that at elevated temperatures, the SKD11 material became softer, with improved ductility and decreased chip flow resistance [18]. This softening effect would result in easier plastic deformation and increase in the machinability of SKD11 hardened steel at high temperatures.

Figure 6 displays the optical images of the wear scar of AlTiN-coated balls after friction tests at different temperatures. As shown in Fig. 6a, many small grooves formed along the sliding direction and some wear debris accumulated inside the wear scar, which indicated that mild abrasive wear and adhesive wear occurred at room temperature. After the friction test at $300{ }^{\circ} \mathrm{C}$, a visible depth groove at the bottom of the wear scar was observed, and the corresponding optical image in Fig. $6 \mathrm{~b}$ exhibits a relatively larger wear scar than that tested at $25^{\circ} \mathrm{C}$. It revealed that the abrasive wear was responsible for the main wear mechanism at this temperature. Meanwhile, an uneven wear scar on the surface of coated ball was also observed, which would be due to the SKD11 materials adhered to the surface of coated ball and gathered on the worn zone in the form of wear debris, causing the threebody sliding between the coated ball and SKD11 hardened steel. After testing at $500{ }^{\circ} \mathrm{C}$, the coated ball was completely worn out, and the damages reached the substrate by numerous scratches appeared on the worn surface, which would be due to the serious abrasive wear occurred and resulted in abrasive wear failure. With the rapid increase in wear rate of the coated ball, the wear debris resulted in the rise of the friction coefficient until the friction reached a steady state, which agreed with the variation of friction curve in Fig. 3. When the wear temperature further increased to $700{ }^{\circ} \mathrm{C}$, the surface of coated ball was covered with large amount of adherent materials transferred from the counterpart, as shown in Fig. $6 \mathrm{~d}$, indicating that the adhesive wear became the main wear mechanism at high temperatures. The chemical composition of the ball surfaces outside the wear scar analyzed by EDS is shown in Fig. 5. It can be clearly seen that no obvious oxidation on the coated ball surface was detected by the EDS analysis when the temperature was below $500{ }^{\circ} \mathrm{C}$, which indicated the good high-temperature oxidation resistance of the AlTiN coating. When the temperature increased to $700{ }^{\circ} \mathrm{C}$, it could be found that a small amount of $\mathrm{O}$ content was detected by the EDS analysis, which implied that the AlTiN coating was partially oxidized and could be classified as mild oxidation wear. As the wear temperature increased, the AlTiN coating was oxidized to form an oxide film layer gradually, acting as an anti-friction and lubrication layer during wear process [17].

According to the wear scar on the AlTiN-coated balls, the depth of wear scar could be calculated by formula (1), as shown in Fig. 7a. As the temperature increased from 25 to $500{ }^{\circ} \mathrm{C}$, the wear scar depth increased from 2.2 to $5.5 \mu \mathrm{m}$, which indicated that the coated ball was more worn when the temperature increased. Compared to the AlTiN coating with a thickness of $4.0 \mu \mathrm{m}$, the coated ball was completely worn out at $500{ }^{\circ} \mathrm{C}$. When the temperature further increased to $700{ }^{\circ} \mathrm{C}$, the wear scar depth decreased sharply to $1.4 \mu \mathrm{m}$. Although there were some micro-uneven scratches and grooves observed on the wear scar surfaces of AlTiN-coated balls, the wear rate of the coated 

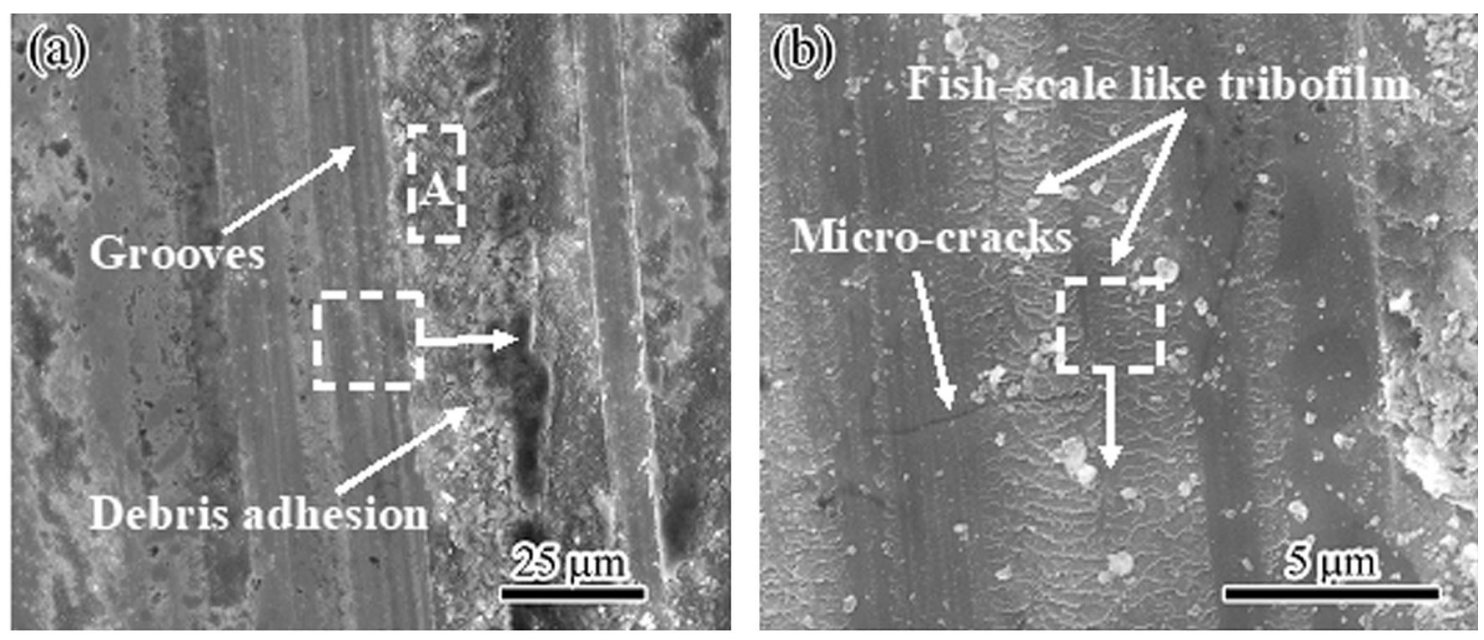

(c)

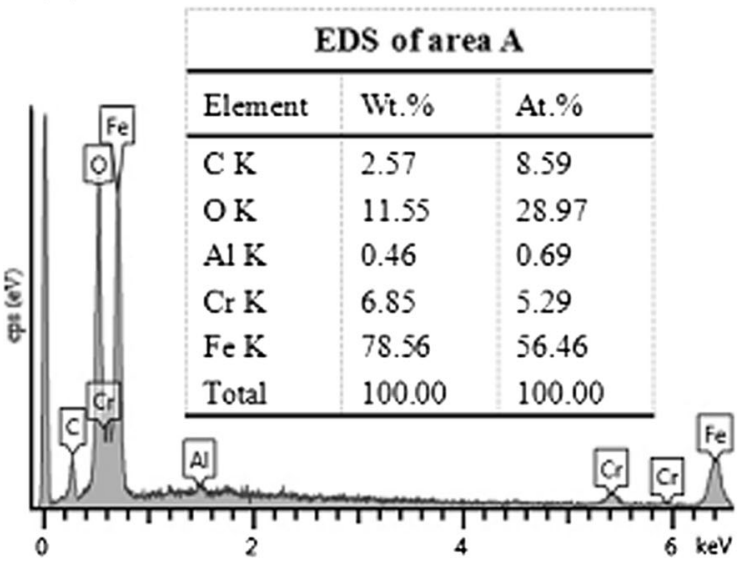

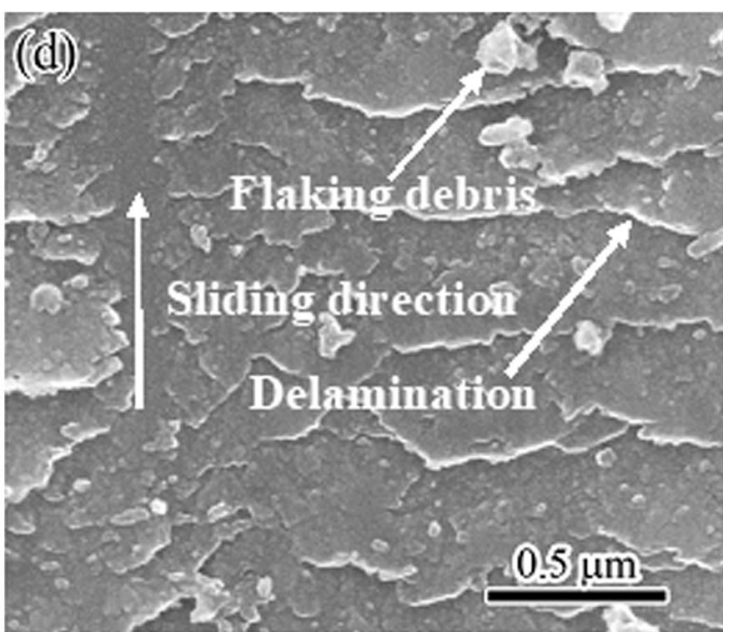

Fig. 8 SEM micrographs and EDS analysis of the wear track of SKD11 hardened steel at $25^{\circ} \mathrm{C}$

ball was still comparable under the different wear temperatures. As shown in Fig. 7b, the wear rate of the AlTiNcoated ball increased from $1.7 \times 10^{-21}$ to $4.3 \times 10^{-21} \mathrm{~m}^{3} / \mathrm{N} \mathrm{m}$ with the temperature increased from 25 to $300{ }^{\circ} \mathrm{C}$. It could be due to the abrasive wear accounted for the main wear mechanism, which usually resulted in a much higher wear rate. As the temperatures further increased to $500{ }^{\circ} \mathrm{C}$, the coated ball was completely worn out, and the wear rate increased sharply to $1.1 \times 10^{-20} \mathrm{~m}^{3} / \mathrm{N} \mathrm{m}$ due to the abrasive wear failure. For the AlTiN coatings, sliding against $\mathrm{Al}_{2} \mathrm{O}_{3}$ ball [15], an obvious decrease in the coating wear rate was observed when the temperature increased from 25 to $550{ }^{\circ} \mathrm{C}$, which could be attributed to the formation of a protective $\mathrm{Al}_{2} \mathrm{O}_{3}$ layer and absence of humidity. Thus, the wear rates of the coatings and balls were closely connected, and the wear debris from the friction materials would be a key factor for wear mechanism [30]. A low wear rate of $7.1 \times 10^{-22} \mathrm{~m}^{3} /$ $\mathrm{N}$ m was achieved as the temperature increased to $700{ }^{\circ} \mathrm{C}$, which could be attributed to the formation of lubricant layer on the AlTiN coating and the high-temperature thermal softening effect of the SKD11 hardened steel. Therefore, the different wear rates of the coated balls could be aroused by the different friction and wear behaviors.

\subsection{Analysis of Wear Track}

The wear track analysis revealed a significant change of the wear mechanisms as a function of the temperature [12]. To further investigate the dominant wear mechanism of the AlTiN-coated balls, SEM and EDS were used to analyze the wear tracks of SKD11 hardened steel tested at different temperatures. As shown in Fig. 8a, the wear track surface was relatively smooth and large amounts of wear debris accumulated on one side of the wear track. This phenomenon illustrated that the wear debris could be ejected out of the friction area easily, which could provide relatively stable friction and wear during the tribological tests at $25^{\circ} \mathrm{C}$. Amplified image in the center of the wear track (Fig. 8b) shows a micro-crack crossing the wear track. It demonstrated that the cracks were generated inside the material and rapidly expanded during loading since the 

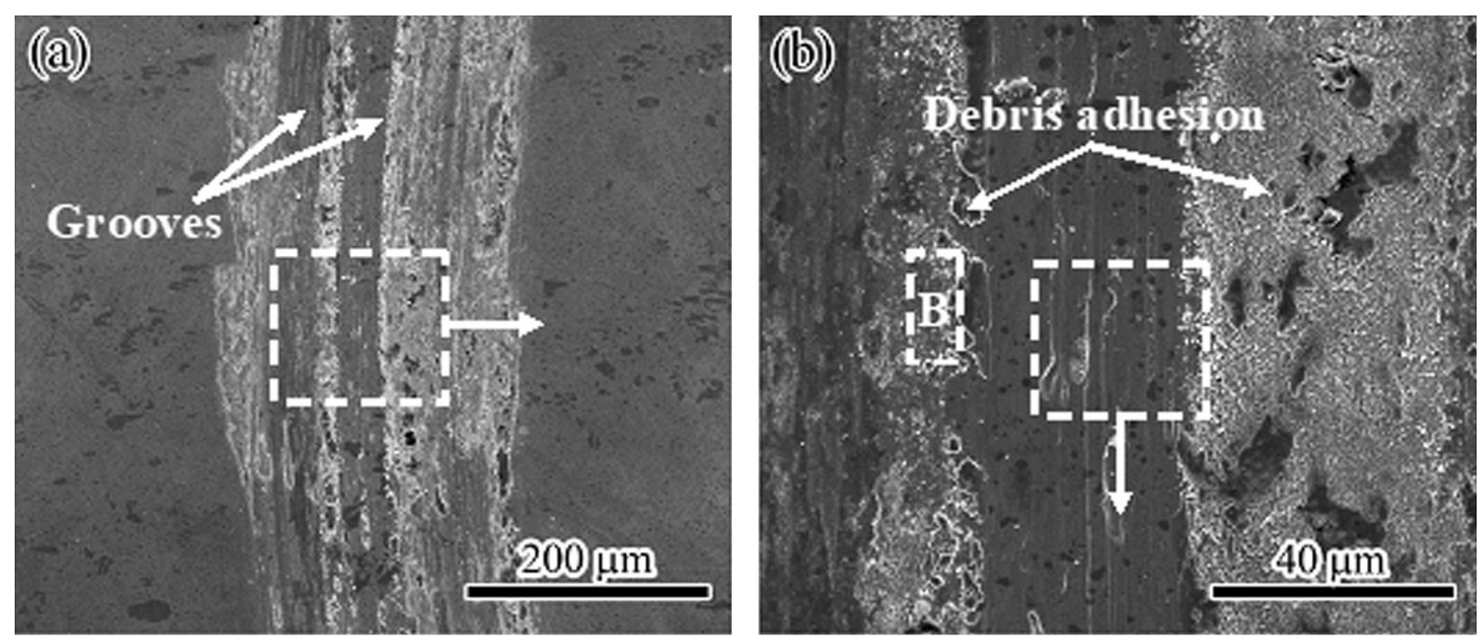

(c)

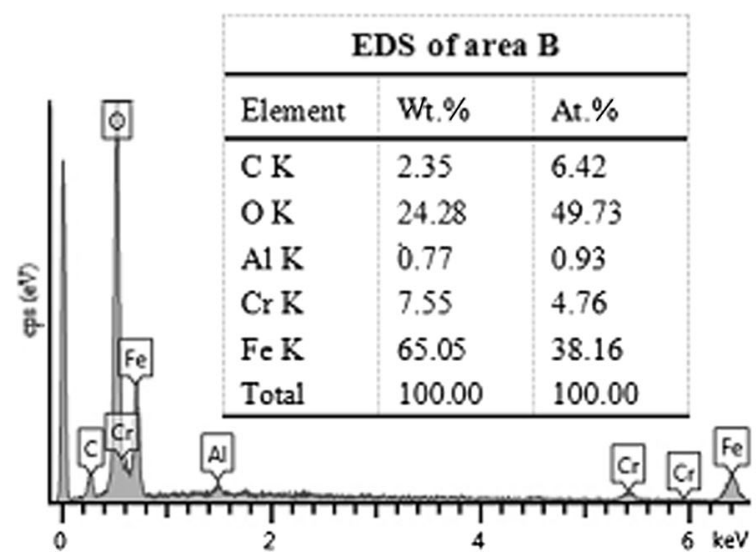

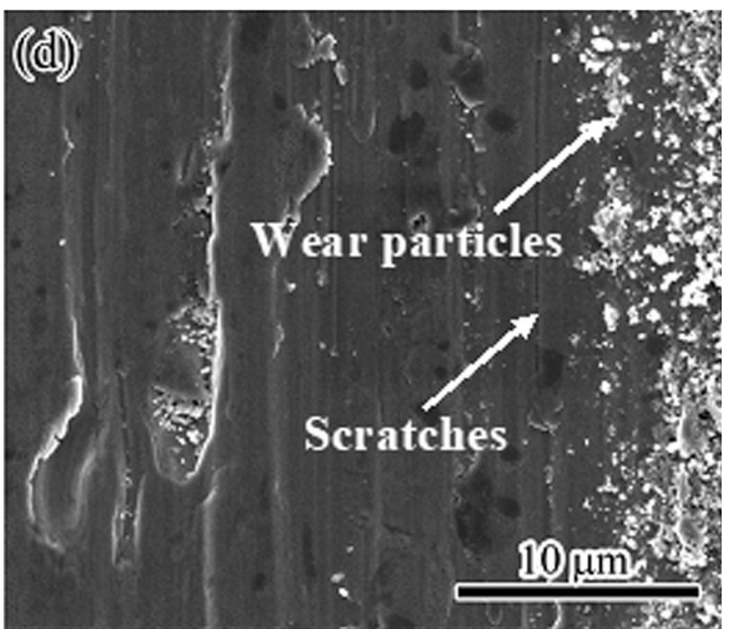

Fig. 9 SEM micrographs and EDS analysis of the wear track of SKD11 hardened steel at $300{ }^{\circ} \mathrm{C}$

plastic deformation capacity of the material was low at this temperature [29]. Figure 8d shows high-magnification examination of the fish-scale-like patterns, which indicated that a thin tribofilm formed along the sliding direction on the worn surface. During the continuous rolling/shearing/ adhesive interactions, the delamination wear would lead to the debris flaking, which were then squeezed by the coated balls to the edge of the wear track. In addition, the EDS analysis of area A (Fig. 8c) shows that the Fe (56.46 at.\%) and $\mathrm{O}$ (28.97 at.\%) elements were detectable in the adhesion zone. Taking into account the high-temperature oxidation resistance of the AlTiN coating, the presence of oxides indicated that the tribo-oxidation phenomenon of SKD11 hardened steel occurred at $25{ }^{\circ} \mathrm{C}$. Meanwhile, the adherence phenomenon was also confirmed by the EDS analysis that a small amount of $\mathrm{Al}$ element was detected in adhesion debris.

Figure 9 shows SEM images and EDS analysis of the wear track of SKD11 hardened steel at $300{ }^{\circ} \mathrm{C}$. As the temperature increased, the hard coated ball could accelerate wear of the relatively soft SKD11 hardened steel, and the easily accumulated wear debris could not be removed out timely, which resulted in the formation of wide grooves in Fig. 9a. Additionally, some wear debris adhered on the wear track surface beside the groove, which can be seen detailedly in Fig. 9b. It could be found that a large amount of $\mathrm{O}$ content inside the wear debris was detected by the EDS analysis at area B in Fig. 9c, implying that the progressive oxidation of SKD11 hardened steel, which enhanced the production of unstable $\mathrm{Fe}$ and $\mathrm{Cr}$ oxides at high temperatures. As shown in Fig. 9d, the amplified image of the groove exhibited a relatively broad surface, in which many fine scratches formed along the sliding direction and wear particles with small size formed on the side, which could be demonstrated as the abrasive wear. The wear particles generated were entrapped subsequently in the sliding contact, causing three-body sliding/rolling abrasive wear of the coating surface and fracturing of the wear particles themselves [20]. Therefore, the primary wear mechanism changed from delamination wear to abrasive wear, which correspondingly led to the increase in the wear rate of the coated balls. 

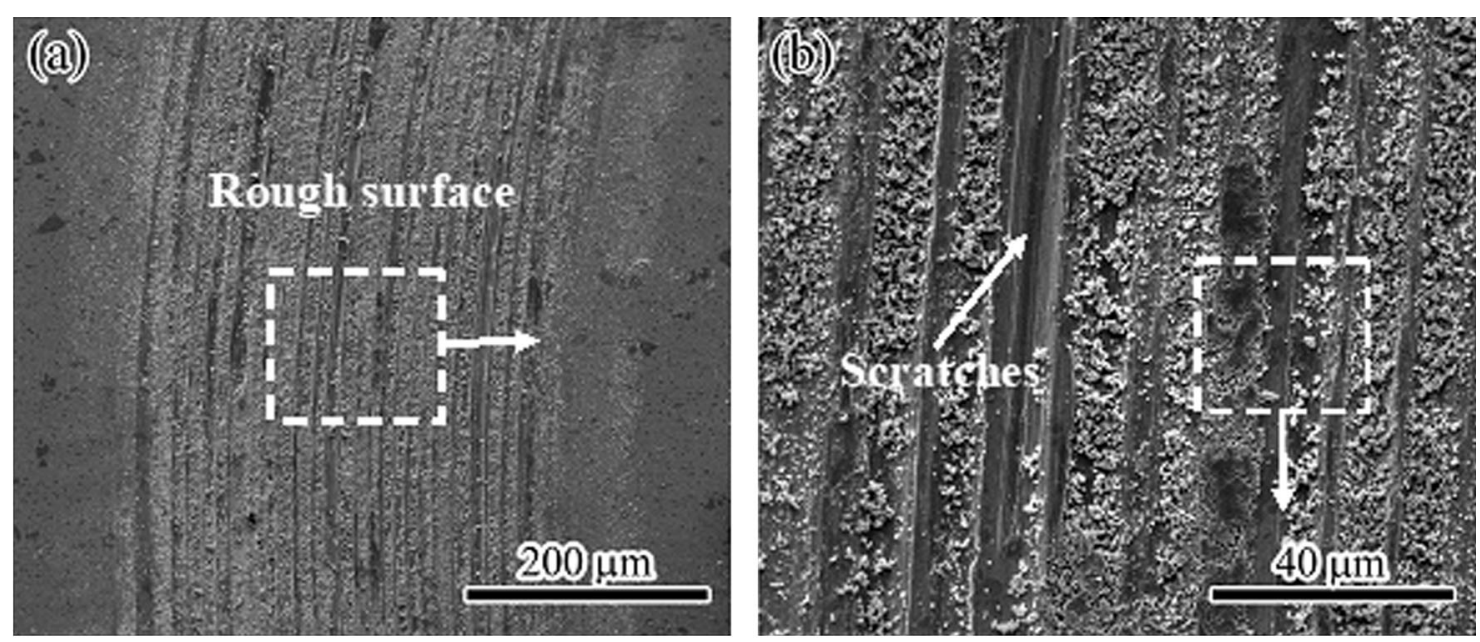

(c)

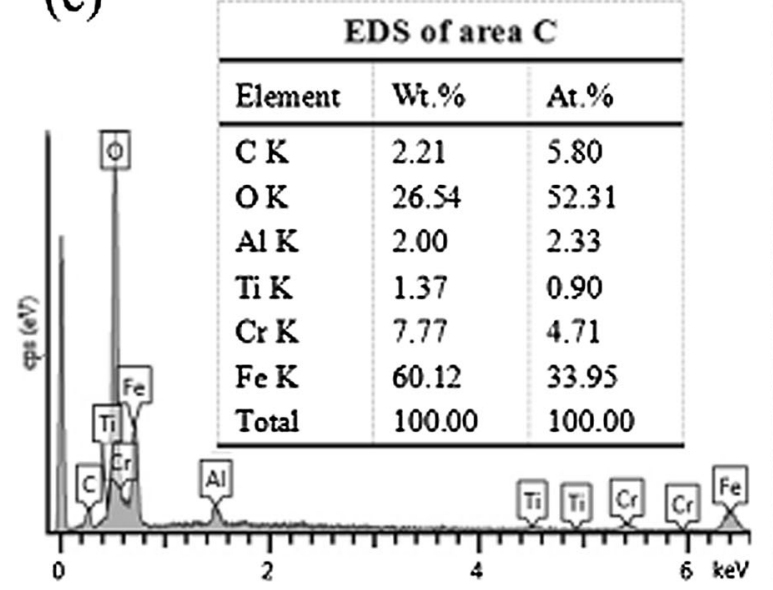

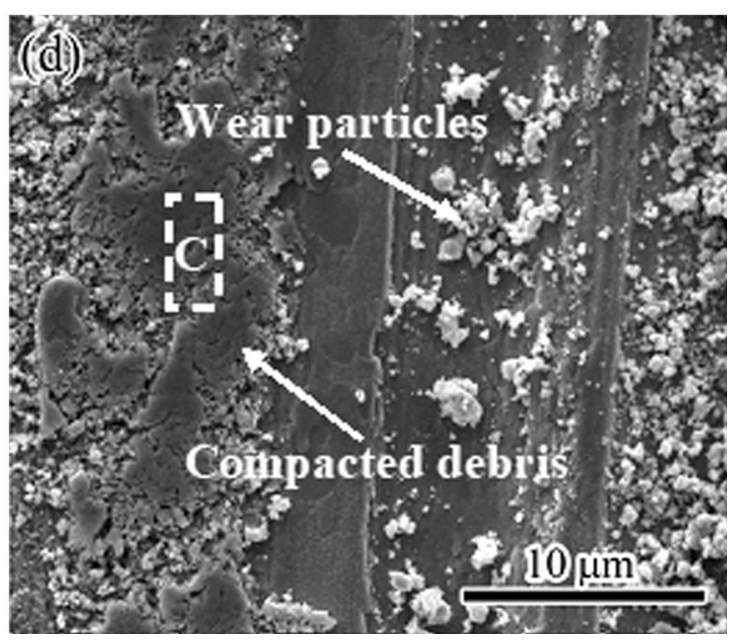

Fig. 10 SEM micrographs and EDS analysis of the wear track of SKD11 hardened steel at $500{ }^{\circ} \mathrm{C}$

As the temperature increased to $500{ }^{\circ} \mathrm{C}$, the coated ball was completely worn out, and the wear track surface of SKD11 hardened steel became much rougher as shown in Fig. 10a. For sliding wear of metals, after the generation and agglomeration of wear particles at the initial wear stage, the severity of sliding friction depends strictly on the adhesive interactions of the wear debris [31]. The wear debris could be adhered together to form wear particles in the wear track, which resulted in many obvious scratches formed along the sliding direction in the wear track in Fig. 10b. As a result, the AlTiN coating continuously fell off from the coated ball, which was typical for abrasive wear failure. When compared to the wear track at $300{ }^{\circ} \mathrm{C}$, a large amount of $\mathrm{Cr}$ and $\mathrm{Fe}$ oxides produced in the wear track to form wear particles with the larger size, as shown in Fig. 10d. Meanwhile, a rough surface with compacted debris was also observed in the amplified image of the wear track, which indicated that the debris was unable to be removed out timely due to the rapid wear rate of the coated ball and resulted in continuously compacted under the cycle sliding load. It was found that considerable accumulations of $\mathrm{Al}$ and Ti element transferred from the coated ball were identified on compacted debris by the EDS analysis at area $\mathrm{C}$ (Fig. 10c), indicating that the wear mechanism of AlTiN-coated ball was primarily composed of abrasive wear, accompanied with mild adhesive wear at $500{ }^{\circ} \mathrm{C}$.

As shown in Fig. 11a, it could be found that furrow surface without visible wear particles formed in the wear track when the temperature further increased to $700{ }^{\circ} \mathrm{C}$, indicating an adhesive wear mechanism. It should be attributed to the oxidation and softening of SKD11 hardened steel which became more severe and resulted in plastic deformation at high temperatures. While the plastic deformation became the mechanical wear mechanism for the AlTiN coatings sliding against $\mathrm{Al}_{2} \mathrm{O}_{3}$ ball at $900{ }^{\circ} \mathrm{C}$ [16]. Therefore, the friction and wear behavior of the coated balls was directly dependent on the counterpart 

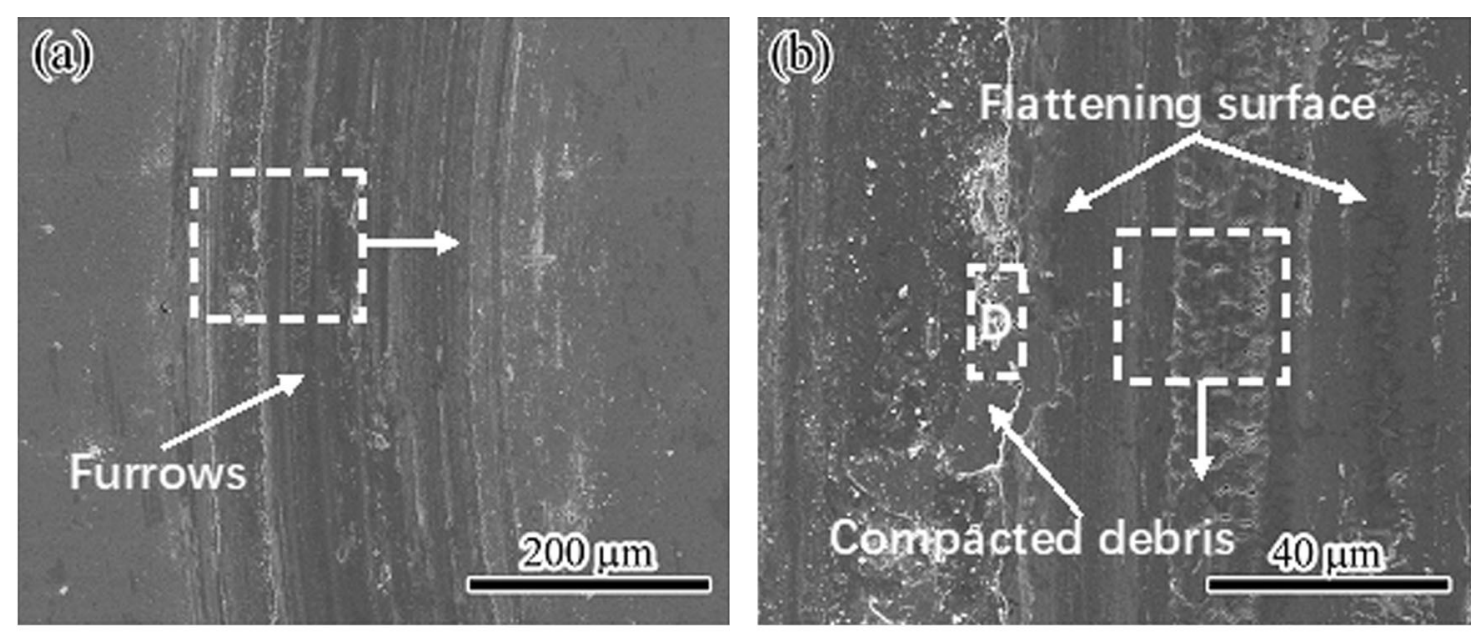

(c)

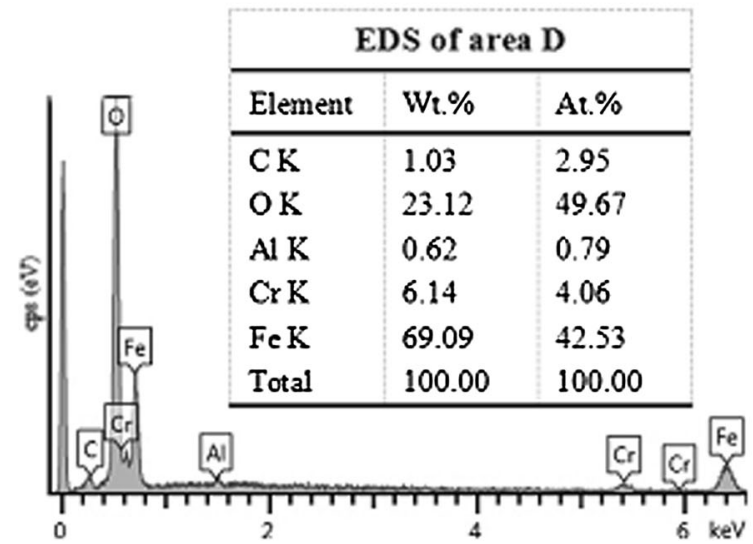

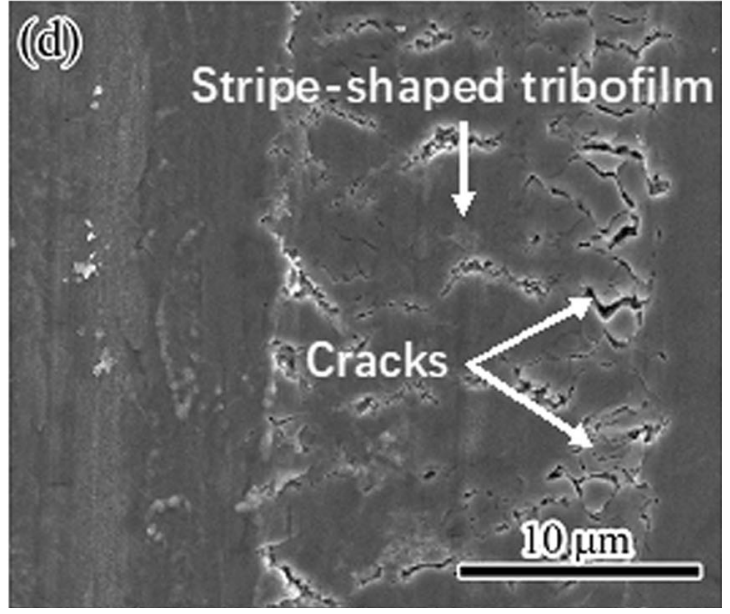

Fig. 11 SEM micrographs and EDS analysis of the wear track of SKD11 hardened steel at $700{ }^{\circ} \mathrm{C}$

materials during the sliding tests. Amplified image of the wear track showed some compacted debris adhered on the edge of wear track, which can be seen detailedly in Fig. 11b. Meanwhile, a small amount of Al element was also detected on the compacted debris by the EDS analysis at area D (Fig. 11c). The ligule adhesion was noted on the worn trace because the Al had a strong chemical activity at the high temperature, and the high Al content in the AlTiN coating was ensured to improve the adhesion between the friction pairs [17]. In addition, a stripe-shaped tribofilm formed along the sliding direction on the flattening surface was also found in Fig. 11b, which would be due to the continuous and repeated plastic flow of the wear debris. During the cycle sliding contact, some of the wear debris would be fractured due to the stress fatigue, and then the cracks would expand gradually. As a result, many obvious cracks were observed on the stripe-shaped patterns in Fig. 11d, showing a fatigue wear mechanism for the SKD11 material.

\section{Conclusions}

The friction and wear behavior of the AlTiN-coated balls against SKD11 hardened steel was investigated by using a ball-on-disk tribometer at elevated temperatures up to $700{ }^{\circ} \mathrm{C}$. The tribological properties were evaluated concerning friction coefficient, surface hardness, wear mechanism and its effect on the wear rate. The major results can be summarized as follows:

1. FCC solid-soluted AlTiN coating with (200) preferred orientation was deposited, which exhibited a relatively high hardness of $33.3 \mathrm{GPa}$.

2. The hardness of AlTiN coating decreased slightly to $31.5 \mathrm{GPa}$ after annealing at $700{ }^{\circ} \mathrm{C}$, while that of SKD11 steel decreased sharply from 768.2 to $362.4 \mathrm{HV}$, which can be attributed to the thermal softening effect at high temperatures.

3. As the temperature increased from 25 to $700{ }^{\circ} \mathrm{C}$, the friction coefficient first increased slightly and then 
decreased, and apparent fluctuations were observed at 500 and $700{ }^{\circ} \mathrm{C}$ due to the formation and rupture of an unstable $\mathrm{Fe}$ and $\mathrm{Cr}$ oxide layers.

4. The wear rate of the coated ball increased from the scale of $10^{-21}$ at $25^{\circ} \mathrm{C}$ to $10^{-20} \mathrm{~m}^{3} / \mathrm{N} \mathrm{m}$ at $500^{\circ} \mathrm{C}$, and then decreased to $10^{-22} \mathrm{~m}^{3} / \mathrm{N} \mathrm{m}$ with increasing the temperature to $700{ }^{\circ} \mathrm{C}$.

5. The primary wear mechanism of AlTiN-coated ball changed from mild abrasive wear and adhesive wear at temperatures of 25 and $300{ }^{\circ} \mathrm{C}$ to abrasive wear failure at $500{ }^{\circ} \mathrm{C}$, and then to adhesive wear and mild oxidation wear at $700{ }^{\circ} \mathrm{C}$ whereas for the SKD11 hardened steel, the main wear mechanism changed from delamination wear to abrasive wear and then transferred to plastic deformation and fatigue wear, accompanied by adhesive wear and tribo-oxidation wear.

Acknowledgements The work was supported in part by the projects of the National Natural Science Foundation of China (Grant No. 51522502), the China Postdoctoral Science Foundation funded project (No. 2016M600641) and the Guangdong Natural Science Funds (Nos. 2014A030311002 and 2016A050502056).

\section{References}

[1] C.W. Kim, K.H. Kim, Thin Solid Films 307, 113 (1997)

[2] Y.C. Chim, X.Z. Ding, X.T. Zeng, S. Zhang, Thin Solid Films 517, 4845 (2009)

[3] H.C. Barshilia, M.S. Prakash, A. Jain, K.S. Rajam, Vacuum 77, 169 (2005)

[4] J. Oliveira, A. Manaia, A. Cavaleiro, Thin Solid Films 516, 5032 (2008)

[5] S. Sveen, J.M. Andersson, R. MSaoubi, M. Olsson, Wear 308, $133(2013)$

[6] A.F. Rousseau, J.G. Partridge, E.L.H. Mayes, J.T. Toton, M. Kracica, D.G. McCulloch, E.D. Doyle, Surf. Coat. Technol. 272, 403 (2015)

[7] Z.P. Huang, Y. Sun, T. Bell, Wear 173, 13 (1994)
[8] M.A. Shalaby, M.A. El Hakim, M.M. Abdelhameed, J.E. Krzanowski, S.C. Veldhuis, G.K. Dosbaeva, Tribol. Int. 70, 148 (2014)

[9] S.Y. Yoon, J.K. Kim, K.H. Kim, Surf. Coat. Technol. 161, 237 (2002)

[10] H. Ohnuma, N. Nihira, A. Mitsuo, K. Toyoda, K. Kubota, T. Aizawa, Surf. Coat. Technol. 177, 623 (2004)

[11] J.L. Mo, M.H. Zhu, B. Lei, Y.X. Leng, N. Huang, Wear 263, 1423 (2007)

[12] T. Polcar, A. Cavaleiro, Surf. Coat. Technol. 206, 1244 (2011)

[13] T. Polcar, N.M.G. Parreira, R. Novák, Surf. Coat. Technol. 201, 5228 (2007)

[14] J.X. Deng, A.H. Liu, Int. J. Refract. Met. Hard Mater. 41, 241 (2013)

[15] Z.T. Wu, P. Sun, Z.B. Qi, B.B. Wei, Z.C. Wang, Vacuum 135, 34 (2017)

[16] Z.B. Qi, P. Sun, F.P. Zhu, Z.T. Wu, B. Lin, Z.C. Wang, D.L. Peng, C.H. Wu, Surf. Coat. Technol. 231, 267 (2013)

[17] D.J. Kong, H.Y. Guo, Tribol. Int. 88, 31 (2015)

[18] C.Y. Wang, F. Ding, D.W. Tang, L.J. Zheng, S.Y. Li, Y.X. Xie, Int. J. Mach. Tool Manuf. 108, 13 (2016)

[19] B.J. Xiao, Y. Chen, W. Dai, K.Y. Kwork, T.F. Zhang, Q.M. Wang, C.Y. Wang, K.H. Kim, Surf. Coat. Technol. 311, 98 (2017)

[20] Q. Luo, Wear 271, 2058 (2011)

[21] C.Y. Wang, Y.X. Xie, L.J. Zheng, Z. Qin, D.W. Tang, Y.X. Song, Int. J. Mach. Tools Manuf 79, 31 (2014)

[22] S.H. Zhang, L. Wang, Q.M. Wang, M.X. Li, Surf. Coat. Technol. 214, 160 (2013)

[23] J. Pelleg, L.Z. Zevin, S. Lungo, Thin Solid Films 197, 117 (1991)

[24] Q.X. Fan, T.G. Wang, Y.M. Liu, Z.H. Wu, T. Zhang, T. Li, Z.B. Yang, Acta Metall. Sin. (Engl. Lett.) 29, 1119 (2016)

[25] H.C. Zhao, Y.B. Ren, J.H. Dong, X.M. Fan, K. Yang, Acta Metall. Sin. (Engl. Lett.) 29, 217 (2016)

[26] Y.S. Hong, S.H. Kwon, T.G. Wang, D.I. Kim, J. Choi, K.H. Kim, Trans. Nonferrous Met. Soc. China 21, S62 (2011)

[27] C.J. Huang, W.Y. Li, M.P. Plance, H.L. Liao, G. Montavon, J. Mater. Sci. Technol. 33, 507 (2017)

[28] M.H. Staia, Y. Pérez-Delgado, C. Sanchez, A. Castro, E. Le Bourhis, E.S. Puchi-Cabrera, Wear 267, 1452 (2009)

[29] F. Ding, D.W. Tang, C.Y. Wang, F.L. Zhang, L.J. Zheng, Trans. Nanjing Univ. Aeronaut. Astronaut. 34, 380 (2017)

[30] A.H. Liu, J.X. Deng, H.B. Cui, Y.Y. Chen, J. Zhao, Int. J. Refract. Met. Hard Mat. 31, 82 (2012)

[31] S.T. Oktay, N.P. Suh, Trans. ASME J. Tribol. 114, 379 (1992) 